\title{
POSITION CHARACTERIZATION OF ELECTRO-PNEUMATIC CLOSED LOOP CONTROL VALVE
}

\author{
Nataraj G.S ${ }^{1}$, Shanmukha Nagaraj ${ }^{2}$, Keshav ${ }^{3}{ }^{3}$ Prakash K.R. $^{4}$ \\ ${ }^{1,2,3}$ Department of Mechanical Engineering, R.V. College of Engineering, Bangalore-59, \\ ${ }^{4}$ Department of Mechanical Engineering, National Institute of Engineering, Mysore \\ nataraj.gsn@gmail.com,shan.nagaraj@gmail.com,keshav.manjunath@yahoo.com
}

\begin{abstract}
This paper presents position characterization of an Electro-pneumatic closed loop control valve BOSCH 0820040001 . The experimental measurements carried out gives pressure gain and the precise position repetition accuracy. A Programmable Logic Controller (PLC) program is developed in ladder logic using IndraLogic L20 software of Rexroth Bosch to determine position repetition accuracy.
\end{abstract}

Keywords - Electro-Pneumatic closed loop control valve, Pressure gain, Precise Position, Repetition accuracy, PLC $* * *$

\section{INTRODUCTION}

The increased automation of small and medium-size series production calls for more flexibility of pneumatic drives. This frequently involves the demand for a stop in any number of intermediate positions between the limit positions or the setting of any forces/ torques and/or the linear or angular velocity using the fluidic quantities of pressure and volumetric flow rate, respectively. At the same time, the required repetition accuracies for the quantities mentioned above must be met since most of the processes are performed cyclically.

Due to the compressibility of air, positioning tasks with switch-off controls (open control loop system) do not yield any satisfactory results in terms of positioning accuracy. The development of highly dynamic continuous valves (regulating valves with flow/directional control properties, continuous pressure valves) used in conjunction with a measuring system for actual value measurements and electronic regulators in a closed control loop results in free positioning as well as pressure and velocity control in production technology and thus also opens new application fields for pneumatics which had so far been reserved to electric or hydraulic drives $[1,2]$.

When the PLC outputs a switching signal, the valve is operated and the piston rod advances. When the signal is switched off, the valve takes on the closed neutral position because of the spring force, thus closing the parts of the cylinder. The piston is held in position by the air columns in the two cylinder chamber. The length of the travelling path can be controlled for a given travel speed by the duration of the control impulse programmed in the PLC so that different positions can be approached [3].
The continuous valve differs from a switching valve (directional control valve) which will take on not only two defined statuses (e.g. open and closed), but it will take on any desired intermediate position between the limit positions. The valve was capable of converting a continuous change in an input signal into a continuous change in output variable i.e. the relationship exists between the input voltage ' $U$ ' and the flow rate ' $Q$ ' or the input voltage ' $U$ ' and the output pressure ' $P$ '.

\section{CLOSED LOOP CONTROL VALVE DETAILS}

BOSCH 0820040001 is a 5/4 way Electro-pneumatic closed Loop Control Valve, with electrically controlled with $5 / 3$ way valve characteristics shown in Fig. 1. The valve has an additional fourth switching position as fail-position, which is assumed when the solenoid is de-energized.

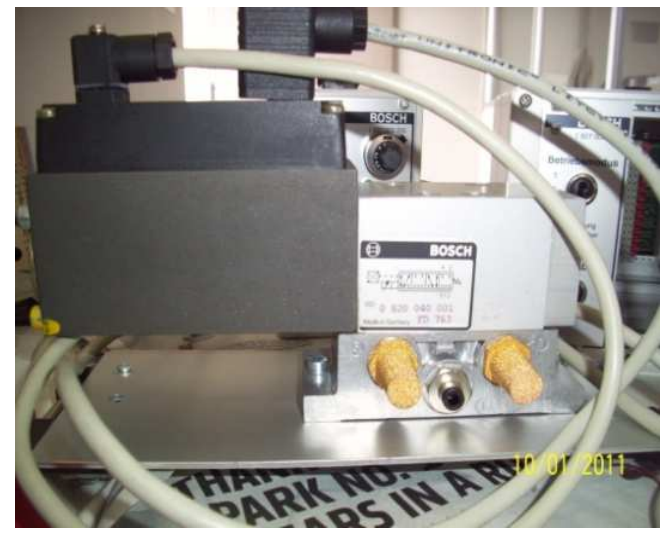

Fig 1 Photograph of Electro-Pneumatic Closed Loop Control Valve 
The opening cross-section of the valve changed across the whole length of the valve slide path ' $y$ ' using an electrical input signal (command value voltage $U=-10 v>0>+10$ ) $U=0$ neutral position.

The regulating valve controlled by a valve amplifier. The electronics basically comprises the following assemblies.

- Position regulation of the valve slide.

- Power supply for solenoid control.

Monitoring and diagnostic functions (e.g. for cable break monitoring). The supply voltage is $24 \mathrm{VDC}$, the power input totals max $35 \mathrm{VA}$.

\section{EXPERIMENTAL CHARACTERIZATION}

\section{RESULTS}

The pressure gain characteristic [4] measures the quality of the zero overlap or the tightness of the valve in neutral position is reflected by the pressure gain. The percentage gain indicates which percentage of the maximum command value signal is required in order to obtain a differential pressure of $80 \%$ of the system pressure at the closed ports. The pressure gain is an important parameter for the rigidity of the drive and its range of inversion.

Fig. 2 shows the testing device used for measuring the desired Characteristics of pressure gain. The Experimental procedure consists of recording command value range $\pm 0.5 \mathrm{v}$. Before carrying out the measurements, set the pneumatic zero point with $\mathrm{U}=0 \mathrm{v}$ the pressure at valve ports $\mathrm{P} 2$ and $\mathrm{P} 4$ must be identical. For this purpose, first turn the command value potentiometer until the digital voltmeter displays $0 \mathrm{v}$. If the pressure gauges show different values for port P2 and P4, adjust the 'null-input' potentiometer at the valve amplifier board until the pressures are identical. Fig. 3 shows the pressure characteristic measured at the regulating valve.

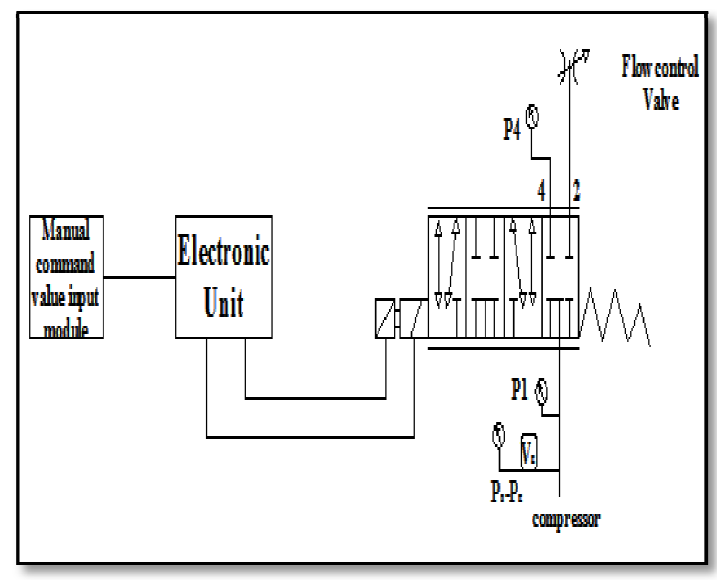

Fig. 2 Testing Device

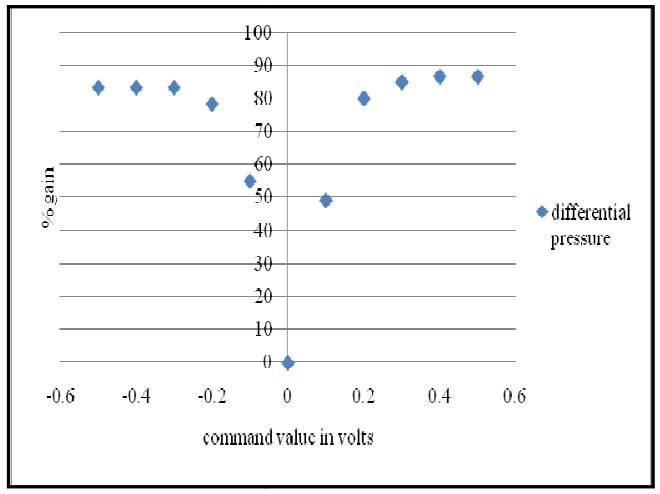

Fig. 3 Pressure Gain Characteristic

Fig. 4 shows an equipment flow sheet of position control. The experimental procedure consists of approaching two different positions precisely. The position were assumed and maintained precisely with different loads. The cylinder was initially operated without the $2 \mathrm{~kg}$ additional mass. For assessing the position accuracy it is useful to first record the stroke characteristic.

The measuring device was attached to the cylinder for this purpose. The pressure transducer cable was disconnected for measuring the position characteristics.

Produce a command value jump with the command value input module. Select command values $\mathrm{Uc} 1=2.5 \mathrm{v}$ and $\mathrm{Uc} 2=$ $6.5 \mathrm{v}$. With these command values it can be ensured that the cylinder movement takes place outside the limit position cushioning and is therefore not influenced by it. Since some parameter setting results in certain instability of the closedloop control, limit position deceleration must be in effect to avoid damages to the cylinder. When the control-loop becomes instable, the enable signal must be turned off. The regulating valve will immediately assume its fail-safe position, and the cylinder is stopped.

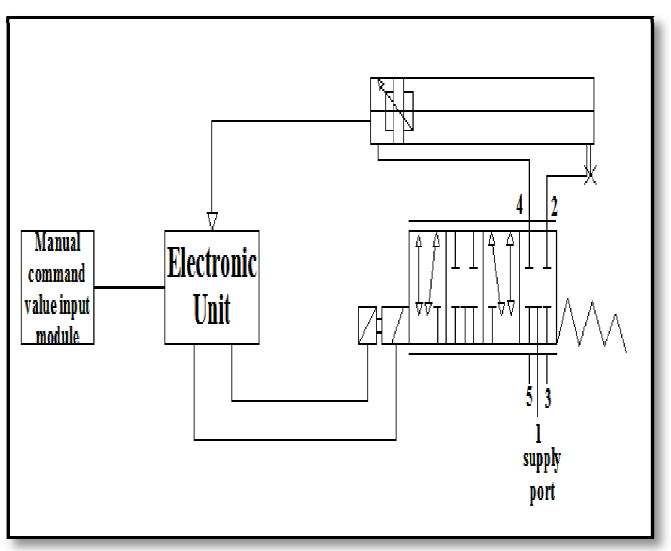

Fig. 4 An Equipment Flow sheet of Position Control. 


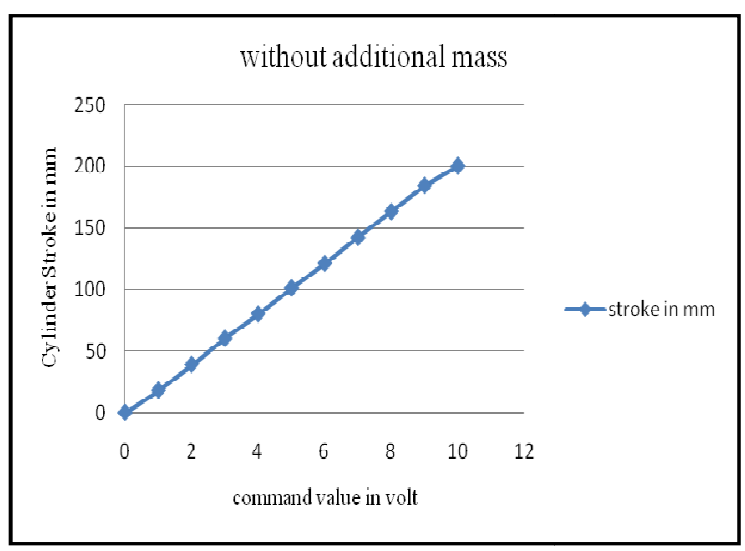

Fig. 5 Cylinder Stroke without additional mass

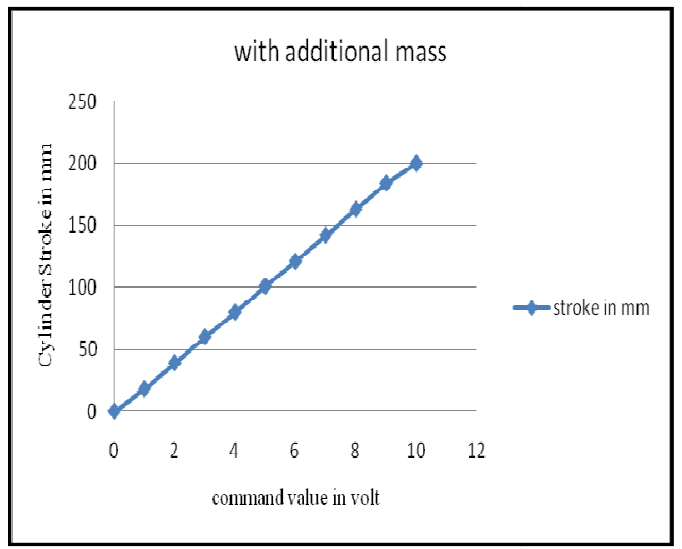

Fig. 6 Cylinder Stroke with additional mass

From Fig. 3 and Fig. 5 it was clear that the additional mass has no influence on the stroke characteristics and there is a linear relation.

\section{Position Control Using PLC}

The characteristics Uactual $=\mathrm{f}(\mathrm{h})$

Uactual $=\mathrm{k} 1 * \mathrm{~h}$

$\mathrm{k} 1=10 \mathrm{v} / 200 \mathrm{~mm}$

$=0.05 \mathrm{v} / \mathrm{mm}$.

The voltage distance between 2 command values is $0.0392 \mathrm{v}$.

This means an achievable minimum distance of $200 \mathrm{~mm} / 255=$ $0.784 \mathrm{~mm}$ between neighbouring positions.

The PLC program was developed in Ladder Diagram Language using Indra LogicL20 software. The cylinder should approach all the positions according to command value starting $0.039 \mathrm{v}$ to $10 \mathrm{v}$ and return to home position. The positioning accuracy of $\pm 1.0 \mathrm{~mm}$ is required. The cylinder driver is to maintain for $5 \mathrm{~s}$ in each one of the position approached.

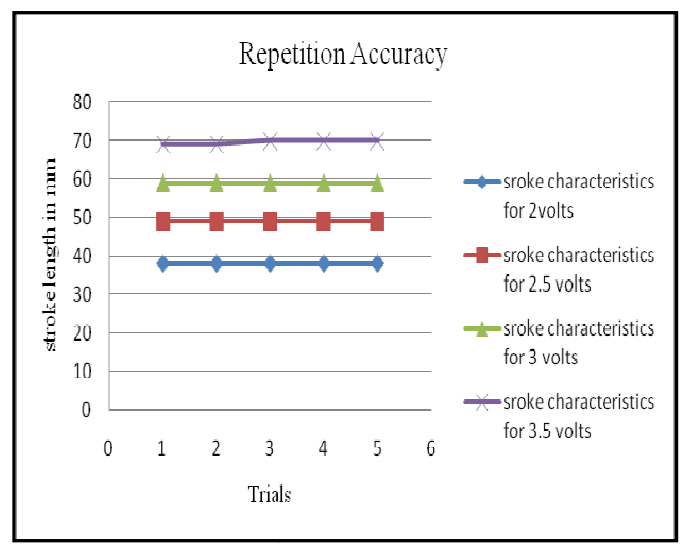

Fig. 7 Repetition Accuracy without additional mass (2 to 3.5v)

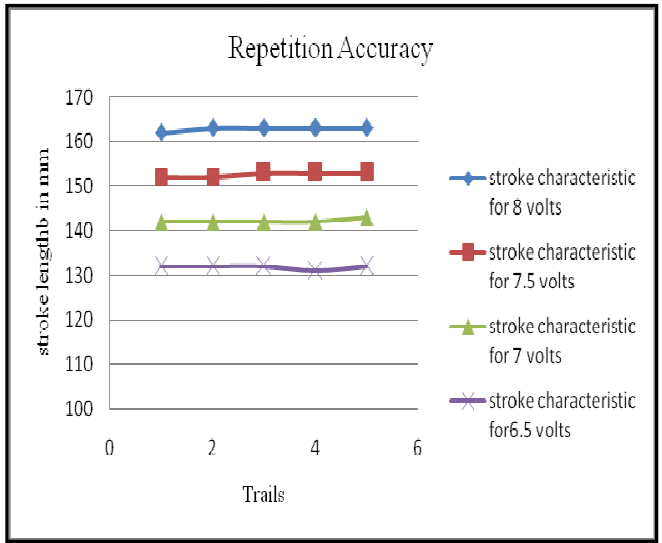

Fig. 8 Repetition Accuracy without additional mass ( 8 to $6.5 \mathrm{v}$ )

Fig. 7 and Fig. 8 show the graph of number of trials and stroke length of the cylinder without additional mass for the command value jump from $2 \mathrm{v}$ to $8 v$. From the Fig. 7 and Fig. 8 it is clear that the command value jump has no influence on the stroke length.

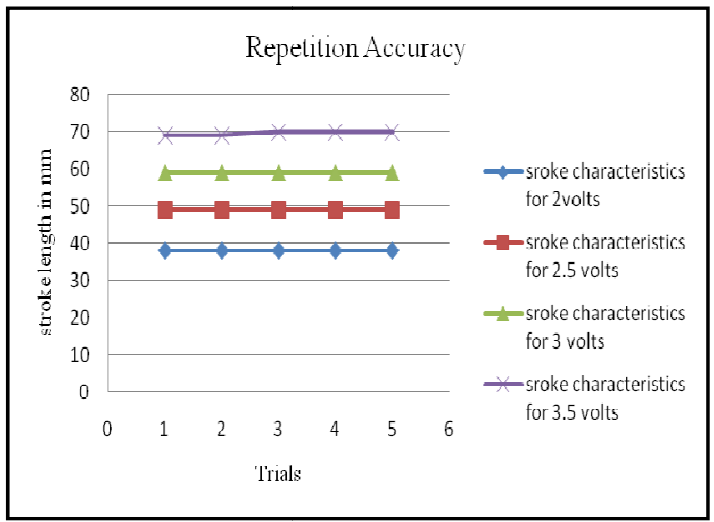

Fig.9 Repetition Accuracy with additional mass (2 to 3.5v) 


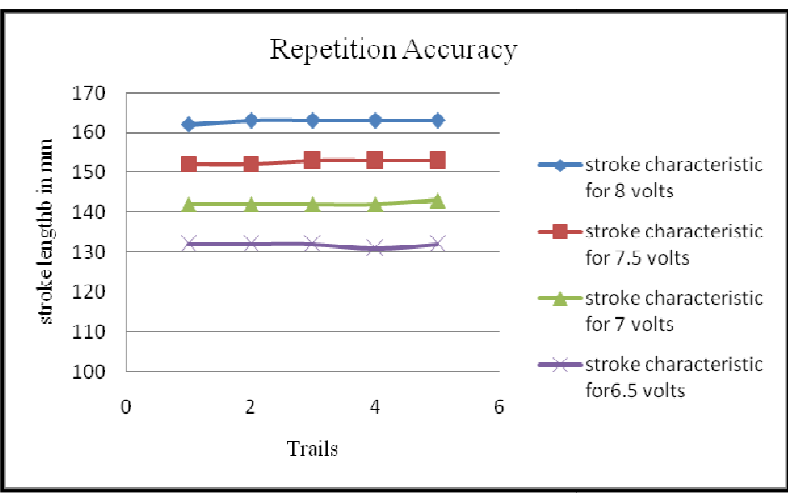

Fig.10 Repetition Accuracy with additional mass ( 8 to $6.5 \mathrm{v}$ )

Fig. 9 and Fig. 10 show the graph of number of trials and stroke length of the cylinder with additional mass $2 \mathrm{~kg}$ for the command value jump from $2 \mathrm{v}$ to 8 v. From the Fig.7 and Fig.8 it is clear that the command value jump and additional mass 2 $\mathrm{kg}$ has no influence on the stroke length and repetition accuracy of position.

\section{CONCLUSIONS}

In this paper position characterisation of $5 / 4$ way electro pneumatic closed loop control valve from the BOSCH company presented. The experimental measurement carried out for a characterization of pressure gain and position repetition accuracy proved the command value jump from $2 \mathrm{v}$ to $8 \mathrm{v}$ and additional mass $2 \mathrm{~kg}$ has no influence on the stroke length and repetition accuracy of position.

\section{ACKNOWLEDGMENTS}

We thank M.S.Santosh Rexroth BOSCH, Bangalore for guiding us throughout the dissertation work.

We also thank Prof. R.S. Kulkarni, Head of the Department, Dept. of Mechanical Engineering R.V.C.E, Bangalore for the kind support held out by him.

\section{REFERENCES}

[1] Osama. Olaby, Xavier. Brun, Sylvie. Sesmat, Tanneguy. Redarce and Eric. Bideaux, characterization and modeling of a proportional valve for control synthesis, Proceedings of the 6th JFPS international symposium on fluid power, 3d1-1 2005, pp 771-776

[2] Saravanan Rajendran, Robert W.Bolton, Position Control of a Servopneumatic Actuator using Fuzzy Compensation, American Society for Engineering Education Annual Conference \& Exposition, Proceedings of the 2003. pp 123-125

[3] Zelijko Situm, Tihomir Zilic and Mario Essert, high Speed Solenoid Valves in Pneumatic Servo Applications, Proceedings of the 15th Mediterranean
Conference on Control and Automation, July 27-29, 2007. pp 34-38.

[4] Osama. Olaby, Xavier. Brun, Sylvie. Sesmat, Tanneguy. Redarce and Eric. Bideaux, characterization and modeling of a proportional valve for control synthesis, Proceedings of the 6th JFPS international symposium on fluid power, 3d1-1 2005, pp 771-776. 